\title{
Elliptic Filter Implementation using Xilinx system Generator for Processing of ECG Signal
}

\author{
Kaustubh M. Gaikwad \\ Assistant Professor, Department of E\&Tc \\ Sinhgad Academy of Enginering Kondhwa,Pune
}

\author{
Mahesh Chavan \\ Professor, Department of Electronics \\ KIT's College of Engineering, Kolhapur
}

\begin{abstract}
Now a day's research has explore in development of prototype devices using different technology. The ECG processing is remained a important research topic as it is useful for the human being directly. Present paper deals with design and implementation of IIR Elliptic digital filter on FPGA for noise reduction in ECG Signal. In this paper filter designed with specifications like order 2 , cutoff frequency $100 \mathrm{~Hz}$. The simulated results and complete step by step design of the filter is depicted in the paper. The results obtained shows the implementation is advantages considering area, power and Speed.
\end{abstract}

\section{General Terms}

Digital signal Processing, ECG, FPGA Technology.

\section{Keywords}

XSG, Elliptic Filter, noise Removal.

\section{INTRODUCTION}

Digital signal processing is promising field from last five decades [5,6]. Growth of DSP started in 1060's. This technology proved today for speed and optimal device utilization for prototype device development. Electrical activity of the heart is generally checked with the help of ECG Signal. ECG Signal provides important information of patient's heart condition. Many times while reading the ECG signal it gets corrupted because of different types of noise signal. Various methods are available for removing these noise contaminated in ECG signal. Many times the IIR and FIR digital filters are used to remove the noise from the ECG Signal There are different methods to remove the noise of the ECG signal which may include digital filters like IIR or FIR filter. Technological development has gifted FPGA technology and it has become more popular for rapid development of prototype devices. FPGA gives reduced board space and system power by reducing system power which leads to optimal device utilization. Field Programmable gate array (FPGA) chips operating speed is considerably large as compare to the DSP. There are top five benefits of the FPGA technology like Performance, Time to Market, Cost, Reliability, and Long-Term Maintenance. Now days this technique is used for implementation of digital filters. Different techniques are used by various researchers for implementation of IIR filter for different applications. In the implementation, representation of coefficients of filters is very important task. M.Z. Ikramet.al explained the method required for amplitude scaling and fixed point format representation [4]. Bahram Rashidi et.al have worked on reduction in power consumption of FIR filter using special adder and multipliers. They synthesized filter using Xilinx ISE Virtex IV FPGA and Xilinx Xpower analyzer [1]. Vladimir M. Poučki at.al have proposed sharpening technique for filter designing for higher order filter using similar low-order filters with same frequency specifications. As per their opinion this technique is used only for linear phase finite impulse response (FIR) filters. In their paper the method is applied on the elliptic IIR which have nonlinear phase. It is seen that transition width is significantly reduced by increase order of the filter. Filters have been implemented on FPGA and hardware folding technique [2]. Suva dip Roy at.al. Implemented a digital moving average filter on FPGA for noise reduction.[3]

This paper demonstrate the implementation of IIR filter using MATLAB Simulink model and Xilinx system generator blocks for high frequency noise reduction in ECG signal.

\section{ELLIPTIC FILTER}

An IIR filter of order $\mathrm{M}$ is generally demonstrated using difference equation,

$y(n)+a_{1} y(n-1)+a_{2} y(n-2)+\cdots+a_{N} y(n-N)=$ $b_{0} x(n)+b_{1}(n-1)+\ldots+b_{M}(n-M) \ldots \ldots .1$ The

Corresponding transfer function

$H(z)=\frac{b_{0} z^{N}+b_{1} z^{N-1}+b_{2} z^{N-2}+\cdots \cdot++b_{M} z^{N-M}}{z^{N}+a_{1} z^{N-1}+a_{2} z^{N-2}+\cdots \cdot+a_{N}} \ldots 2$

These type of the filters are flexible than the FIR filter because of their feedback from previous output. As compared to FIR, denominator provides freedom in shape and response of the filter. Therefore design of IIR filter is simpler. These filters works on the approximations like Butterworth, Chebyshev and Elliptic. The Elliptic approximation has equiripple response in both passband and stopband. The frequency response magnitude of the elliptic filter of the order $\mathrm{N}$ is given by

$$
\left|H_{N}\left(e^{j \omega}\right)\right|=\left[\frac{1}{1+\varepsilon^{2} G_{N}\left[\tan (\omega / 2) / \tan \left(\omega_{c} / 2\right)\right]^{2}}\right]^{1 / 2}
$$

where $G_{N}(x)$ is a rational elliptic filter of the order N, $\omega_{C}$ is the cutoff frequency, and $\varepsilon$ is a parameter which affects the passband ripples. It is possible to synthesize the this filter in matlab using code $[B, A] \operatorname{elip}\left(N, R_{p}, R_{s}, W_{n}\right.$ 'ftype'). Similarly order of the filter can be calculated using code $[\mathrm{N}, \mathrm{Wn}]=$ ellipord(Wp,Ws,Rp,Rs). This filter has unique property that they gives lowest filter order for given setoff specifications. If this filter is compared with FIR optimal filter which giving equiripple Frequency response. Therefore these filters are more preferred in IIR filters for various applications. These filters have some limitations that they have less linear phase in pass band as compare to Butterworth or chebyshev filter. 


\section{DIGITAL FILTER INFORMATION}

The digital filter information is given below in tabular form, the table 1 describes the detail information of Butterworth filter used for design, and whereas table 2 shows filter specifications used during implementation of filter, table 3 shows actual implementation cost in terms of number of components such as multipliers and adders used.

Table 1: Elliptic Filter Information

\begin{tabular}{|l|l|}
\hline Filter structure & Direct form II \\
\hline Number of sections & 1 \\
\hline Filter Stability & Stable \\
\hline Linear Phase & No \\
\hline Design algorithm & Ellip \\
\hline
\end{tabular}

Table 2: Filter Design Specifications

\begin{tabular}{|l|l|}
\hline Sampling frequency Fs & $1000 \mathrm{~Hz}$ \\
\hline Filter response & Low pass \\
\hline Filter order & 2 \\
\hline Pass band edge & .2 \\
\hline 3dB point & 0.23963 \\
\hline 6dB Point & 0.28599 \\
\hline Stopband edge & 0.97207 \\
\hline Pass band ripple & $1 \mathrm{db}$ \\
\hline Stop band attenuation & $80 \mathrm{db}$ \\
\hline Transition width & 0.77207 \\
\hline
\end{tabular}

Table 3: Filter Implementation Cost

\begin{tabular}{|l|l|}
\hline Number of Multipliers & 4 \\
\hline Number of adders & 4 \\
\hline Number of states & 2 \\
\hline Multiplication per input sample & 4 \\
\hline Addition per input sample & 4 \\
\hline
\end{tabular}

\section{DESIGN SCHEME}

To design elliptic filter for denoising ECG signal the filter order is taken 2 and the cut off frequency taken is $100 \mathrm{~Hz}$. To get proper sampling and avoiding aliasing effect sampling frequency taken is $1000 \mathrm{~Hz}$. Elliptic filter gives equiripple response in the pass and stop band.

\subsection{Realization of Filter}

The figure 1 shows design of Elliptic filter using FDA Tool whereas figure 2 shows realization model of the filter.

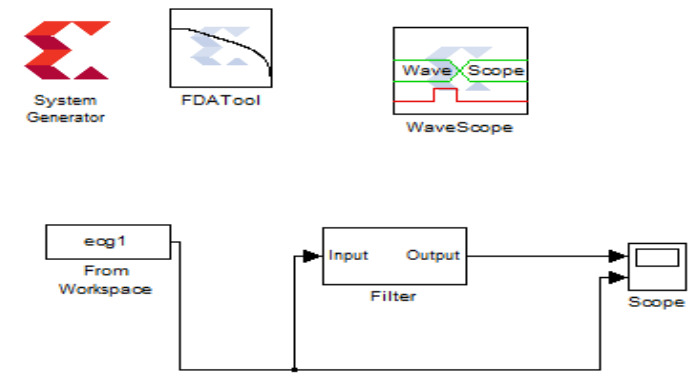

Fig.1: Design of IIR Elliptic filter using FDA tool

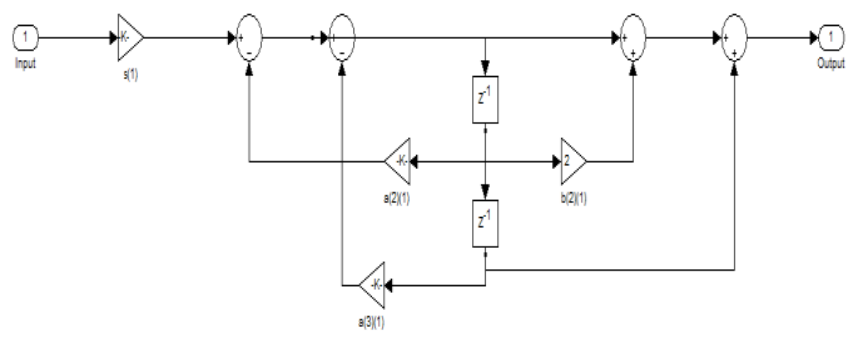

Fig.2: Realization model of IIR Elliptic Low pass filter using FDA Tool

\subsection{Implementation Steps:}

Design of low pass filter using FDA Tool

Create Simulink Model using Xilinx System Generator.

Identify the Filter Coefficients.

Complete the simulation model using Xilinx basic

elements (Xilinx system generator block is compulsory)

Execute the model ad observe the waveform on Scope.

Get Detail summary report which includes the device utilization, Time and power analysis.

Get RTL Schematic of the Designed filter

Fig.3: Implementation steps 


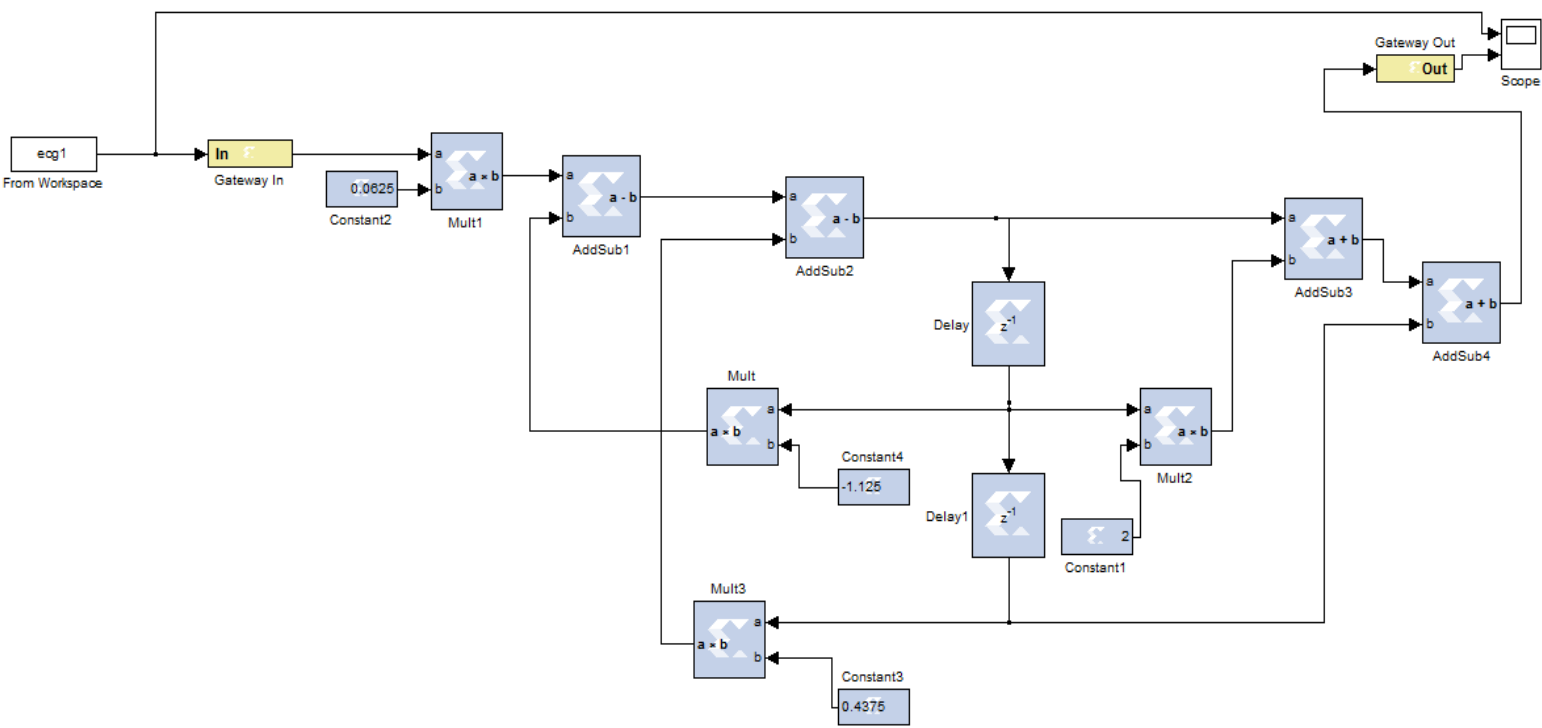

Fig.4 : IIR Elliptic Low pass filter using Xilinx System Generator

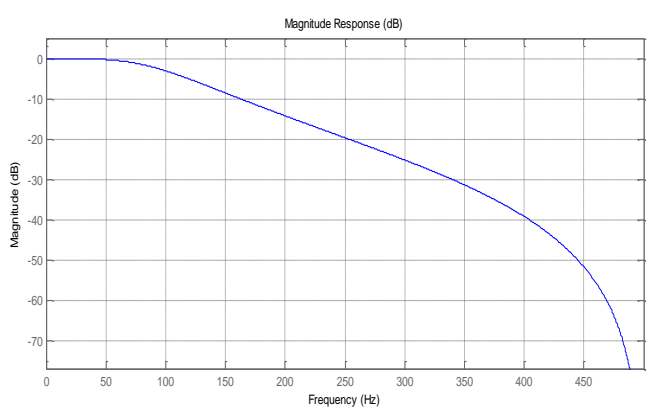

Fig.5a: Magnitude Response

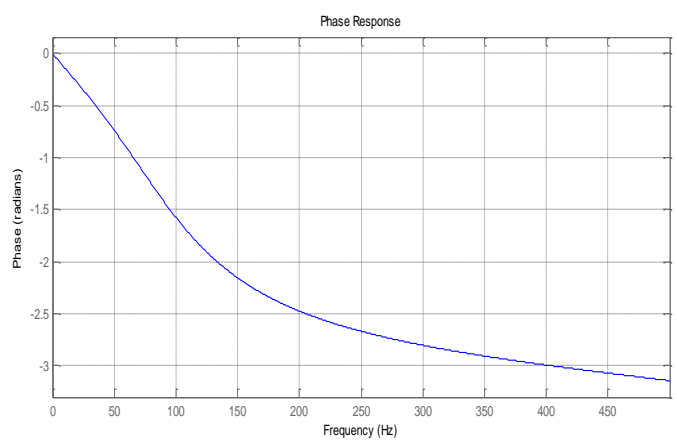

Fig.5b: Phase response

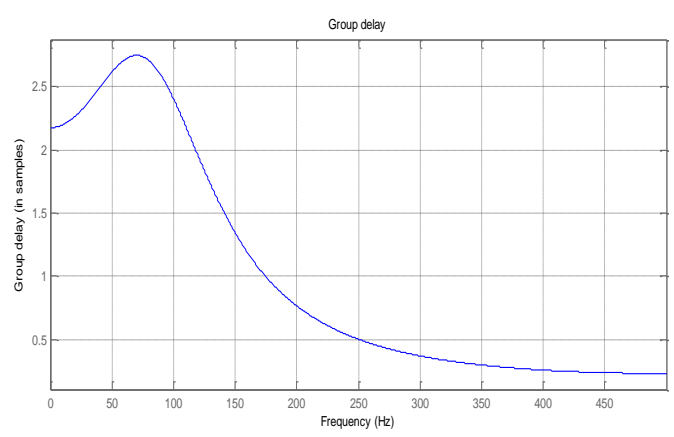

Fig.5c: Group Delay Response

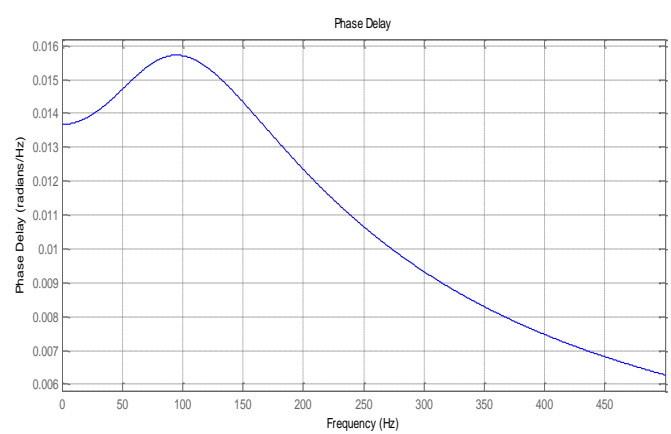

Fig.5d: Phase Delay Response

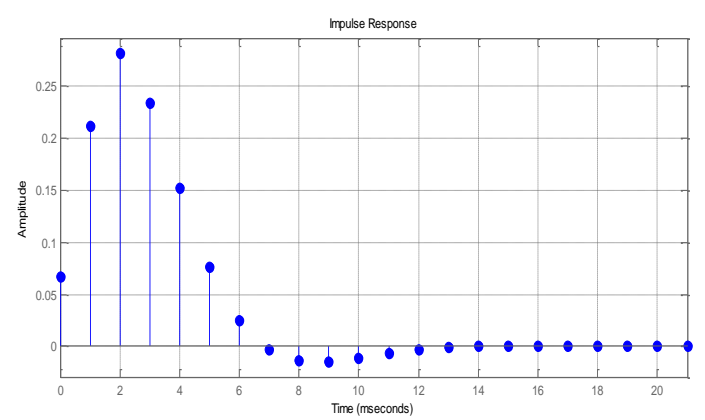

Fig.5e: Impulse Response

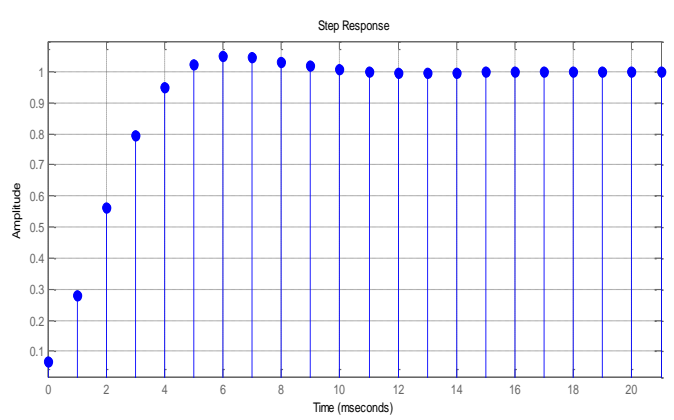

Fig.5f: Step Response 


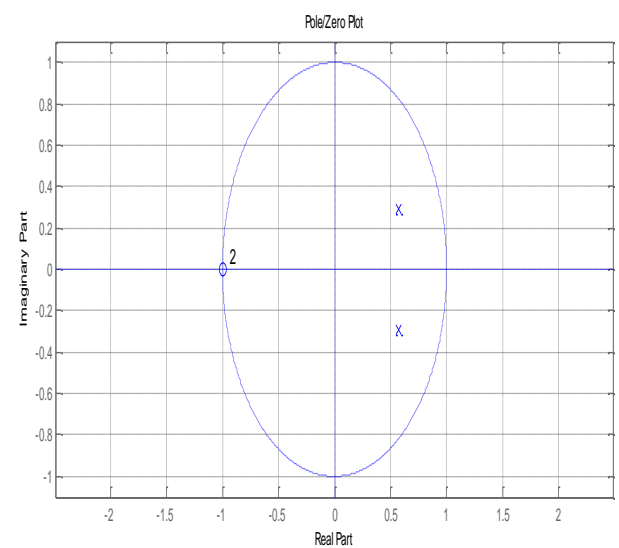

Fig.5g: Pole Zero Diagram

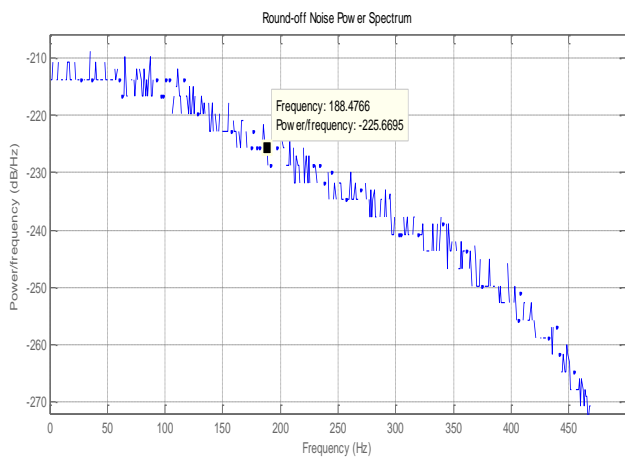

Fig.5h: Round off Noise power Spectrum

\section{IMPLEMENTATION RESULTS}

In this Filter ECG Signal is applied with High Freq Noise, The Figure 6 Shows Input \& Output Waveforms before and after Filtration Where Noise above $100 \mathrm{~Hz}$ Is Filtered.

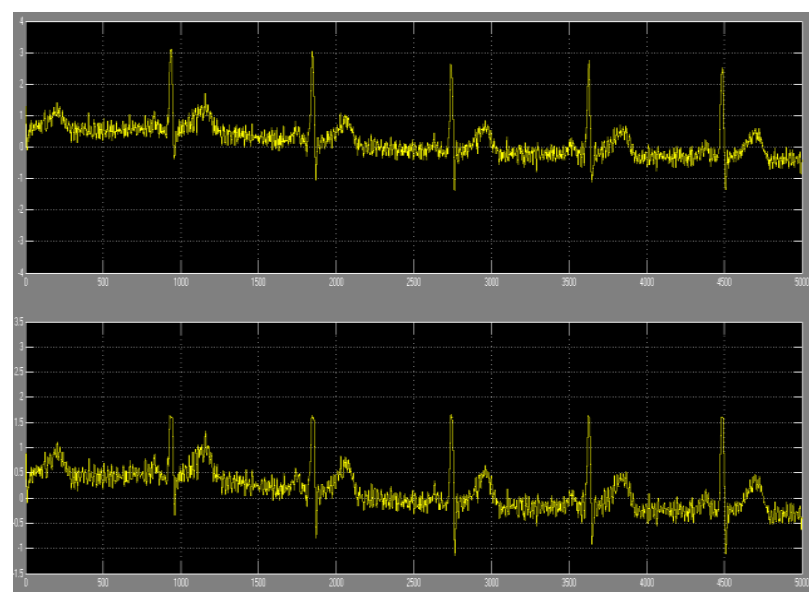

Fig.6: Input \& Output waveforms of digital filter

\subsection{RTL Schematic}

Figure 7 shows the RTL Schematic of the proposed filter.
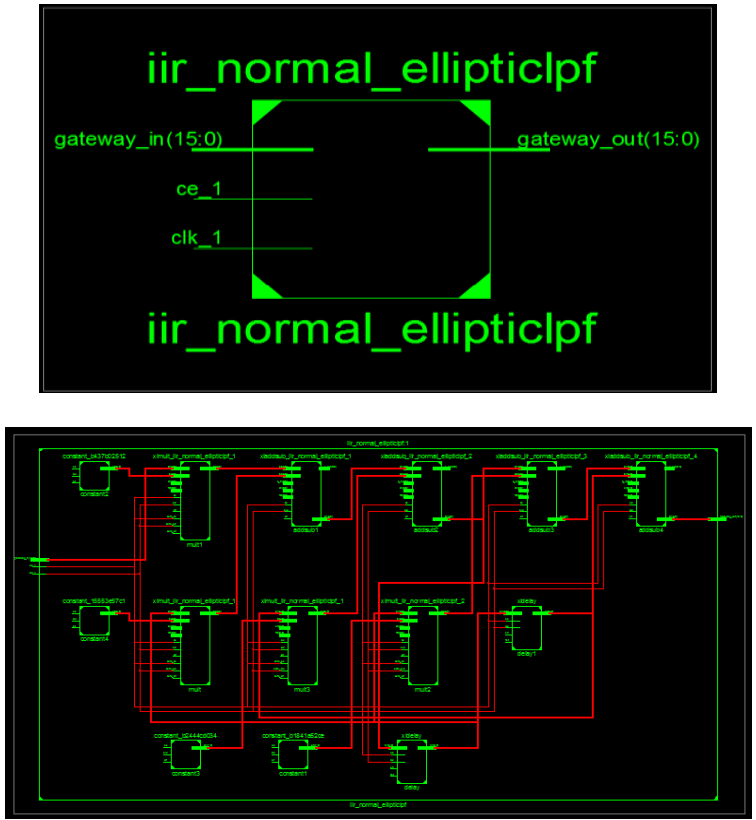

Fig.7: RTL Schematic

\subsection{Device Utilization Summary}

\begin{tabular}{|c|c|c|c|}
\hline Target Device: & \multicolumn{3}{|l|}{3 s500efg320-4 } \\
\hline Product & \multicolumn{3}{|l|}{ ISE 14.2} \\
\hline $\begin{array}{l}\text { Logic } \\
\text { Utilization }\end{array}$ & Available & Used & Utilization \\
\hline $\begin{array}{l}\text { Number of } \\
\text { Slice Flip Flops }\end{array}$ & 9,312 & 4 & $1 \%$ \\
\hline $\begin{array}{l}\text { Number of } 4 \\
\text { input LUTs }\end{array}$ & 9,312 & 23 & $1 \%$ \\
\hline $\begin{array}{l}\text { Number of } \\
\text { occupied Slices }\end{array}$ & 4,656 & 40 & $1 \%$ \\
\hline $\begin{array}{l}\quad \text { Number of } \\
\text { Slices } \\
\text { containing only } \\
\text { related logic }\end{array}$ & 40 & 40 & $100 \%$ \\
\hline $\begin{array}{l}\text { Number of } \\
\text { Slices } \\
\text { containing } \\
\text { unrelated logic }\end{array}$ & 40 & 0 & $0 \%$ \\
\hline $\begin{array}{l}\text { Total Number } \\
\text { of } 4 \text { input } \\
\text { LUTs }\end{array}$ & 9,312 & 72 & $1 \%$ \\
\hline $\begin{array}{l}\text { Number used } \\
\text { as logic }\end{array}$ & & 23 & \\
\hline $\begin{array}{l}\text { Number used } \\
\text { as a route-thru }\end{array}$ & & 49 & \\
\hline $\begin{array}{l}\text { Number of } \\
\text { bonded IOBs }\end{array}$ & 232 & 33 & $14 \%$ \\
\hline $\begin{array}{l}\text { Number of } \\
\text { BUFGMUXs }\end{array}$ & 24 & 1 & $4 \%$ \\
\hline $\begin{array}{l}\text { Average } \\
\text { Fanout of Non- } \\
\text { Clock Nets }\end{array}$ & & 1.04 & \\
\hline
\end{tabular}




\section{CONCLUSION}

In this paper low pass IIR Elliptic filter is designed and implemented for denoising the ECG signal using XSG Platform. It has been observed that filter shows good performance in terms of various parameters such as area, speed and power consumption. The filter implemented with Vedic multiplier can be used for various biomedical applications out of which one is used for denoising of ECG Signal. In future different order IIR and FIR filters can be implemented using Vedic multiplier for different applications.

\section{REFERENCES}

[1] Bahram Rashidi,Bahman Rashi,Majid Pourormazd,"Desi gn andImplementation of LowPower Digital FIR Filter based on low power multipliers and adders on xilinx FPGA" 3rd International Conference on Electronics Computer Technology (ICECT), 2011, Kanyakumari pp $18-22$.

[2] Vladimir M. Poučki, Andrej Žemva, Miroslav D. Lutovac "Elliptic IIR filter sharpening implemented on FPGA" Digital Signal Processing Vol. 20, Issue 1,January 2010, pp13-22.

[3] Suvadip Roy, L. Srivani, D. Thirugnana Murthy, "Digital Filter Design Using FPGA" International Journal of Engineering and Innovative Technology (IJEIT) Volume 5, Issue 4, October 2015

[4] M.Z. Ikram, Siddiqui N.A, K. A. Meraim, Hia Y."Design and implementation of IIR filters in STLC7545 analog front-end for voice communication" Proceedings of IEEE Region 10 Annual Conference on Speech and Image Technologies for Computing and Telecommunications., Brisbane, Qld., Australia, vol.1 pp. $65-67$.

[5] C. Rader, "DSP history - the rise and fall of recursive digital filters," IEEE Signal Process. Mag., vol. 23, pp. 46-49, Nov. 2006.

[6] B. Gold and C.M. Rader, "Digital filter design techniques in the frequency domain," Proc. IEEE, vol. 55, no. 2, pp. 149-171, Feb. 1967.

[7] Michael Francis, "Infinite Impulse Response Filter Structures in Xilinx FPGAs" Xilinx WP330 (v1.2) August 10, 2009.

[8] C. Saritha, V. Sukanya, Y. Narasimha Murthy "ECG Signal Analysis Using Wavelet Transforms", Bulg. J. Phys. 35 (2008) 68-77.

[9] L. Cromwell, F.J. Weibell, E.A. Pfeiffer (2005) Biomedical Instrumentation and Measurements, Prentice Hall of India, New Delhi

[10] Harish V. Dixit, Dr. Vikas Gupta, "IIR filters using Xilinx System Generator for FPGA Implementation", International Journal of Engineering Research and Applications Vol. 2, Issue 5, September- October 2012, pp.303-307.

[11] Anurag Aggarwal, Astha Satija, Tushar Nagpal, "FIR Filter Designing using Xilinx System Generator",
International Journal of Computer Applications Volume 68-No.11, April 2013

[12] Kumudini Sahu, Rahul Sinha," FIR Filter Designing using MATLAB Simulink and Xilinx system Generator" International Research Journal of Engineering and Technology (IRJET) Volume: 02 Issue: 08 Nov-2015.

[13] Gaikwad, S.R., Gawande, G. S. "Design and Implementation of Efficient FIR Filter Structures using Xilinx System Generator" International Journal of scientific research and management (IJSRM) Volume2,Issue-3,Pages-599-604.

[14] Patel, S."Design and Implementation of 31-order FIR Low-pass Filter using Modified Distributed Arithmetic based on FPGA" International Journal of Advanced Research in Electrical, Electronics and Instrumentation Engineering Vol. 2, Issue 10, ISSN: 2320 - 3765.

[15] Ayesha Firdous, Dr.B.Rajan, "A Comparative Study of Pipelining Techniques for Recursive Filter Implemented in FPGA", International Journal of Scientific \& Engineering Research, Volume 5, Issue 4, April-2014 pp.330-333.

[16] Chi-Jui Chou, Satish Mohanakrishnan, Joseph B.Evans,"FPGA Implementation of Digital Filters,", Proc.ICSPAT'93.

[17] Emmanuel S. Kolawole, Warsame H.Ali, Penrose Cofie, John Fuller, C. Tolliver, Pamela Obiomon, " Design and Implementation of Low-Pass, High-Pass and Band-Pass Finite Impulse Response (FIR) Filters Using FPGA" Circuits and Systems, 2015, 6, 30-48.

[18] Sushmitha.C, Swathy.R, Veena Devi.S, Esther Jeba Rani.S.A, Nagaraju.N , "Design and Simulation of FIR Filter", International Journal of Innovative Research in Science, Engineering and Technology,Volume 5, Special Issue 2, March 2016, pp 241-245.

[19] Shahnam Mirzaei, Anup Hosangadi, Ryan Kastner , "FPGA Implementation of High Speed FIR Filters Using Add and Shift Method" International Conference on Computer Design, pp 308-313.

[20] Sweety Kashyap, Mukesh Maheshwari, "Implementation of High Performance FIR Filter Using Low Power Multiplier and Adder" Int. Journal of Engineering Research and Applications Vol. 4, Issue 1( Version 1), January 2014, pp.177-181.

[21] Kaustubh M. Gaikwad, Mahesh S. Chavan "Vedic Mathematics for Digital Signal Processing Operations A Review" International Journal of Computer Applications (0975 - 8887) Volume 113 - No. 18, March 2015.

[22] Mahesh Chavan, R. A. Agarwala, M.D. Uplane" Application of chebyshev Type II digital filter for noise reduction in ECg Signal" Proceedings of the $5^{\text {th }}$ WSEAS international Conference on Signal Processing, computational Geometry and Artificial Vision”, Malta, Sept.15-17,2005 pp 2-8. 